\title{
Diode Laser Ablation Versus Surgical Scalpel Technique For Gingival Depigmentation: A Randomized Controlled Clinical Trial
}

\section{Bayan Habli, Msc}

Beirut Arab University, Lebanon

Nahed Attia, PhD

Beirut Arab University, Lebanon

\section{Mohamed Shokry, PhD}

Beirut Arab University, Lebanon

Submitted: 24 July 2020

Accepted: 28 September 2020

Published: 31 October 2020

Corresponding author:

Bayan Habli

DOI: 10.19044/esj.2020.v16n30p87

Copyright 2020 Habli et al.

Distributed under Creative Commons CC-BY 4.0 OPEN ACCESS

\begin{abstract}
:
The aim of this study is to evaluate and compare the clinical efficiency of gingival depigmentation procedure with conventional scalpel and diode laser techniques.
\end{abstract}

Materials and methods: This study was carried out as a randomized controlled clinical trial, split mouth design, in which fifteen patients having diffuse continuous physiologic pigmentation of the gingiva involving facial aspect of maxillary right to left premolar area were selected. The maxilla was divided into two halves and randomly allotted for "study site" for depigmentation with diode laser technique, and "control site" for depigmentation with scalpel technique. The studied variables were the degree of pain, bleeding, duration of the procedure, wound healing, and level of melanin repigmentation. The follow-up period was twelve months. For statistical analysis, Wilcoxon signed-rank test were conducted.

Results: The diode laser technique showed better results regarding pain during the first three days, duration of the procedure, and bleeding. There was no significant difference between diode laser technique and scalpel technique regarding the wound healing and pain experienced by the patient after one week of surgery. Both sites showed recurrence of pigmentation, yet it was after a shorter period on the scalpel site.

Conclusion: The findings of the present study suggest that gingival depigmentation was effective with both 
scalpel and laser techniques. However, the laser treated sites showed reduced pain experienced by the patient and better operator comfort. Melanin repigmentation was observed on sites treated with scalpel and diode laser, yet faster on the scalpel technique sites.

\section{Subject:}

Keywords: Depigmentation; Diode laser; Repigmentation; Gingiva; Esthetics

\section{Introduction:}

Gingival health and appearance are essential components of an attractive smile. Gingival pigmentation is a discoloration of the gingiva due to a variety of lesions and conditions associated with several endogenous and exogenous etiologic features (Kauzman et al., 2004).

Gingival pigmentation may be classified as physiologic (ethnic/racial) or pathologic. Physiologic pigmentation occurs due to greater melanocyte activity rather than greater number of melanocytes. Attached gingiva is the most common site of such pigmentation (Kauzman et al., 2004).

Pathologic gingival pigmentation can be the result behind several factors or diseases of which are endocrine disease (Addison's disease) (Fiorelline et al., 2011), exposure to heavy metals (Fiorelline et al., 2011), a variety of medications (drug induced) (Bortuluzzi et al., 2007), long standing inflammatory mucosal lesions (lichen planus) (Kauzman et al., 2004), smoking associated melanosis which is of the most encountered (Hedin and Larsson, 1987),

hemangioma (Kauzman et al., 2004), iatrogenic causes including accidental displacement of amalgam in oral soft tissues (Meleti et al., 2008), oral melanoacanthoma (Carlos-Bregni et al., 2007), haemochromatosis membrane (Carlos-Bregni et al., 2007).

Different procedures have been proposed for gingival depigmentation. Roshni \& Nandakumar in 2005 classified different gingival depigmentation methods as methods used to remove the gingival pigmentation, including surgical methods like scalpel surgical technique, bur abrasion method, electrosurgery, cryosurgery, lasers, and radiosurgery; and chemical methods, and methods used to mask the gingival pigmentation like free gingival graft and acellular dermal matrix allograft (Malhotra et al., 2014).

The scalpel method is one of the most economic techniques and also does not require extensive armamentarium. Moreover, it is known that the healing period for scalpel wounds is faster than other techniques (Javali et al., 2011). However, scalpel surgery causes bleeding during and after the procedure. 
Though the initial results of depigmentation procedure are highly encouraging, repigmentation is a possibility.

Laser ablation of gingival depigmentation has been recognized as one of the effective, pleasant and reliable techniques (Prabhuji et al., 2011). It is usually sufficient to eliminate the pigmented areas and does not require any periodontal dressing (Javali et al., 2011). It also shows reduced pain and discomfort due to formation of protein coagulum. Meanwhile, it allows clean and dry operating field and stable results (Simsek Kaya et al., 2012). However, it has its own disadvantages of delayed wound healing, thermal damage, deep penetration and the comparably high costs of the procedure (Kumar et al., 2013).

In light of the above information, this study was conducted in order to evaluate and compare the clinical efficiency of gingival depigmentation procedure with conventional scalpel technique and diode laser technique.

Materials and Methods:

This study was carried out as randomized controlled clinical trial, split mouth design. Allocation of quadrants into "study site" and "control site" was done randomly through using computerized generated randomization table (www.randomizer.org). On the study site, gingival depigmentation was performed by diode laser, while on the control site, gingival depigmentation was performed by scalpel technique.

After receiving the approval from the Institutional Ethical Council, and after university Institutional Review Board approval (IRB code: 2019-0065D-M-0306), a total of fifteen patients between the ages of 18 and 50 were selected from the outpatient clinics of the Oral and Surgical Sciences Department Division of Periodontology at Beirut Arab University, Faculty of Dentistry, Beirut, Lebanon. Patients were selected to fulfill inclusion and exclusion criteria. Inclusion criteria: diffuse continuous physiologic pigmentation of the gingiva involving facial aspect of the maxillary right to left premolar area, periodontally healthy patients, age between 18 and 50 and including both genders. Exclusion Criteria: pregnant and lactating women, medically compromised patients, smokers, patients having history of postsurgical keloid, patients in whom gingival hyper-pigmentation was associated with other syndromes, lesions, and conditions (like occupational hazards) and patients with any metallic restoration or undergoing orthodontic treatment.

The patients were diagnosed according to Dummett-Gupta oral pigmentation (DOP) (1964) index and the level of gingival hyperpigmentation was graded (figure 1). They were informed about the nature of the study and signed an informed consent.

All patients underwent oral prophylaxis and were asked to follow oral hygiene instructions. The depigmentation procedure was performed using 
diode laser (Biolase epic diode laser $940 \mathrm{~nm}$ wavelength, USA) on the study site and the scalpel on the control site.

Figure 1: Diffuse medium clinical pigmentation with DOP score 2.
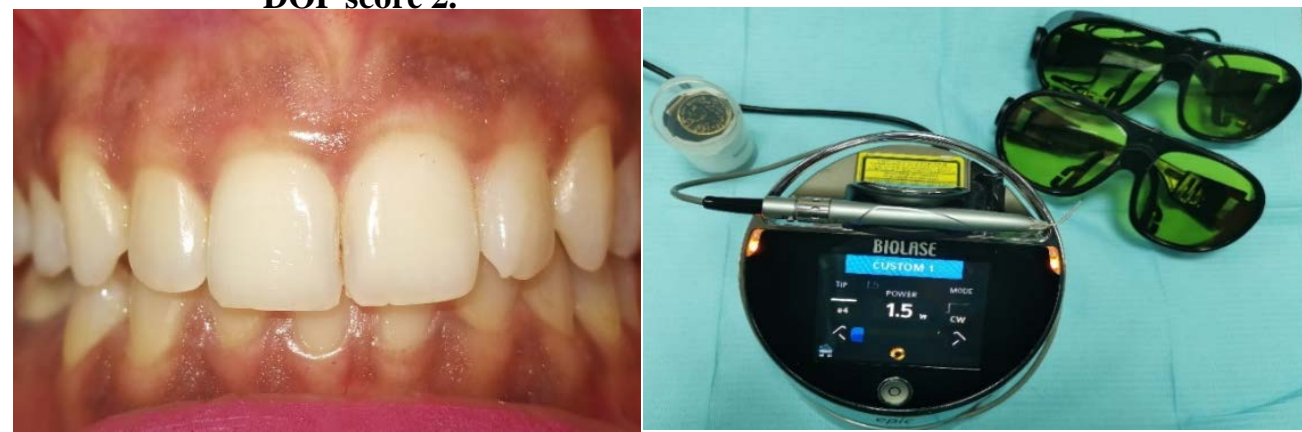

Diode Laser Procedure (Study Site): The depigmentation was carried out using Biolase epic diode laser $940 \mathrm{~nm}$ wavelength machine (figure 2). The area was anesthetized using $20 \%$ lidocaine gel (figure 3). The laser beam was operated under the following parameters: continuous wave mode, initiated tip, power setting of $1.5 \mathrm{~W}$ and energy $120 \mathrm{~mJ}$. Laser safety protocols were followed as per Food and Drug Administration (FDA) guidelines. The laser tip was used in contact mode on the pigmented part of the gingiva. The ablation was performed using paint brush strokes from the mucogingival junction to the free gingival margin. High suction tip was kept close to working area in order to aspirate fumes and heat (figure 4). Sterile gauze soaked in saline was used to remove the char formed over the surface of the surgical area. Thorough examination was carried out to make sure all the pigmented epithelium was removed (Suragimah et al., 2016).

Figure 3: Topical anesthesia application on study site (right side).

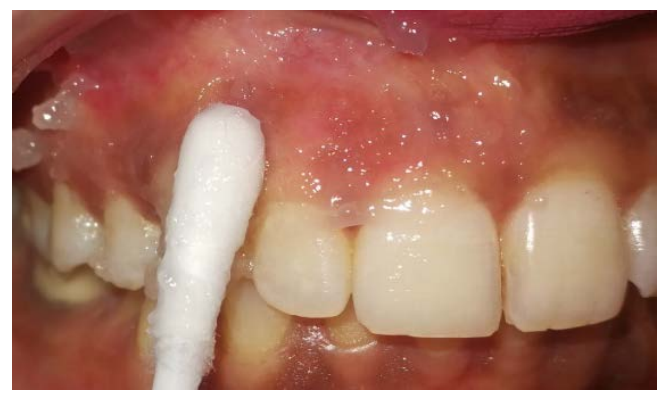

Figure 4: Gingival depigmentation by diode laser on study site (right side).

Scalpel Procedure (Control Site): Local anesthesia was obtained with infiltration (2\% Lidocaine with adrenaline 1:2,00,000) (Lignospan standard, Septodont) in relation to the surgical site (figure 5). The gingival epithelium 
was excised with Bard Parker blade number 15. The excision involved the entire pigmented area extending from the free gingival margin to the mucogingival junction from the midline extending to the first premolar, with the blade placed almost parallel to the long axis of the teeth with care taken not to expose the underlying bone (figure 6). Orban's knife (Osung, Korea) was used to remove the residual epithelium in the interdental areas and the remaining tissue tags were removed using surgical scissors. Bleeding was controlled by using pressure packs to achieve hemostasis (Harpreet et al., 2014).

Figure 5: Local anesthesia infiltration on control site (left side).

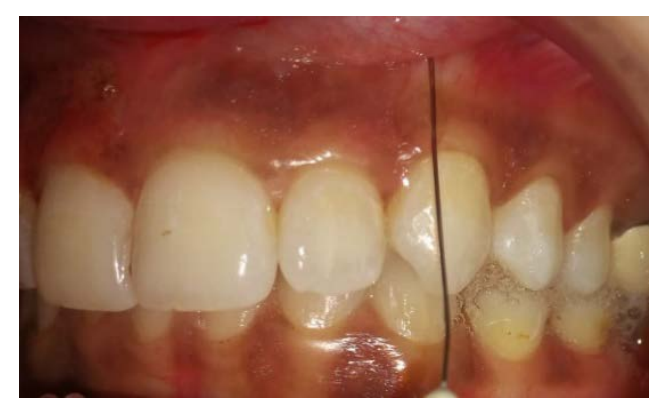

Figure 6: Gingival depigmentation by scalpel on control site (left side).

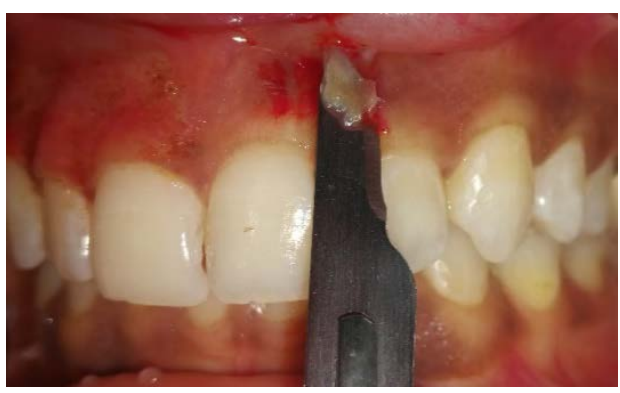

Patients were instructed to avoid the consumption of hot and spicy foods for the first 24 hours and were advised to use chlorohexidine mouth wash twice a day for one week. Analgesic (400 mg ibuprofen (Brufen, Abbot Laboratories Limited, UK)) was prescribed according to the severity of pain (Suragimah et al., 2016). Follow-up visits were done at day three and seven post-operative, and three, six, and twelve months.

\section{Methods of Scoring:}

The pain experienced during the procedure was recorded immediately after the procedure and also on the third and seventh day. The subjects were asked to rate the degree of pain on a $10 \mathrm{~cm}$ horizontal visual analog scale (VAS) with two endpoints where $0=$ no pain and $10=$ worst pain possible.

Bleeding was assessed immediately after the procedure. A clean, dry wound was recorded as " $0=$ no bleeding", wound with mild oozing of blood " 1 = oozing", and bleeding sufficient to fill the mouth with blood frequently "2 = active bleeding” (Varghese et al., 2015).

Duration of the procedure from start of incision/laser application till the end of the procedure was recorded in minutes.

Wound healing was assessed on the third and seventh days after the procedure as per Healing Index of Landry, Turnbull and Howley (table 1) (figures 7, 8, 9) (Bansal et al., 2016) (Chawla et al., 2016) (Pippi 2017). 
Table 1: wound healing as per Healing Index of Landry, Turnbull and Howley.

\begin{tabular}{|c|c|c|c|c|c|}
\hline $\begin{array}{c}\text { Healing } \\
\text { index }\end{array}$ & $\begin{array}{c}\text { Tissue } \\
\text { color }\end{array}$ & $\begin{array}{c}\text { Bleeding } \\
\text { on } \\
\text { palpation }\end{array}$ & $\begin{array}{c}\text { Granulati } \\
\text { on tissue }\end{array}$ & Incision margin & $\begin{array}{c}\text { Suppurati } \\
\text { on }\end{array}$ \\
\hline Poor & $\begin{array}{c}\geq 50 \% \text { of } \\
\text { red } \\
\text { gingiva }\end{array}$ & Yes & Yes & $\begin{array}{c}\text { Loss of } \\
\text { epithelium } \\
\text { beyond incision } \\
\text { margin }\end{array}$ & Yes \\
\hline 2.Poor & $\begin{array}{c}\geq 50 \% \text { of } \\
\text { red } \\
\text { gingiva }\end{array}$ & Yes & Yes & $\begin{array}{c}\text { Exposed } \\
\text { connective } \\
\text { tissue }\end{array}$ & No \\
\hline 3. Good & $\begin{array}{c}25 \text {-50\% of } \\
\text { red } \\
\text { gingiva }\end{array}$ & No & No & $\begin{array}{c}\text { No exposed } \\
\text { connective } \\
\text { tissue }\end{array}$ & No \\
\hline $\begin{array}{c}\text { 4.Very } \\
\text { Good }\end{array}$ & $\begin{array}{c}\text { red } \\
\text { gingiva }\end{array}$ & No & No & $\begin{array}{c}\text { No exposed } \\
\text { connective } \\
\text { tissue }\end{array}$ & No \\
\hline $\begin{array}{c}\text { 5.Excell } \\
\text { ent }\end{array}$ & $\begin{array}{c}\text { All pink } \\
\text { tissues }\end{array}$ & No & No & $\begin{array}{c}\text { No exposed } \\
\text { connective } \\
\text { tissue }\end{array}$ & No \\
\hline
\end{tabular}

Gingival pigmentation was assessed at baseline, three months, six months, and twelve months (figures 10,11,12) according to DOP index as follows: Score 0: pink tissue (no clinical pigmentation) Score 1: mild light brown tissue (mild clinical pigmentation) Score 2: medium brown or mixed brown and pink tissue (moderate clinical pigmentation)

Score 3: deep brown/blue-black tissue (heavy clinical pigmentation). 
Figure 7: right side is study (laser) site and left side is control (scalpel) site, surgery day (baseline).

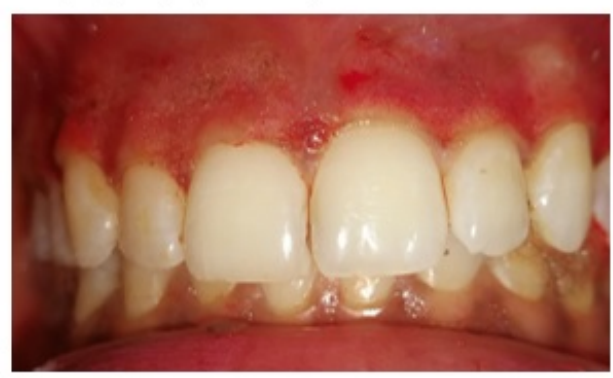

Figure 9: wound healing after 1 week of gingival depigmentation. Score 5 at both sites.

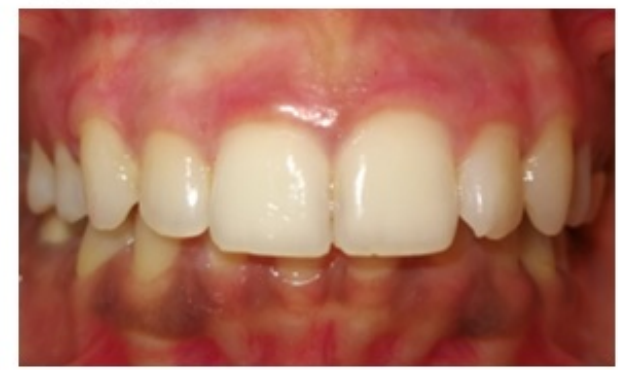

Figure 11: Gingival pigmentation assessment 6 months after surgery. DOP score 0 at study site and score 1

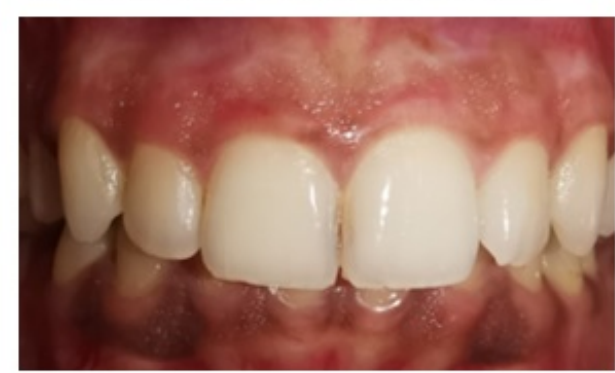

Figure 8: wound healing after 3 days of gingival depigmentation. Score 3 on study site and score 4 on control site.

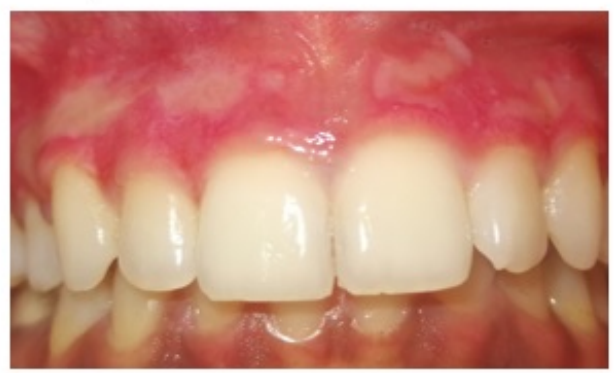

Figure 10: Gingival pigmentation assessment 3 months after surgery. DOP score 0 at both sites.

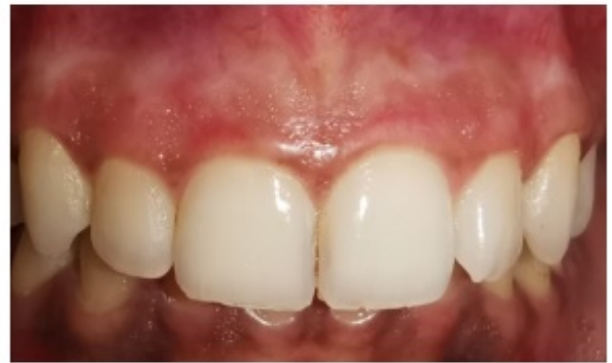

Figure 12: Gingival pigmentation assessment 12 months after surgery. DOP score 0 at study site and score 1

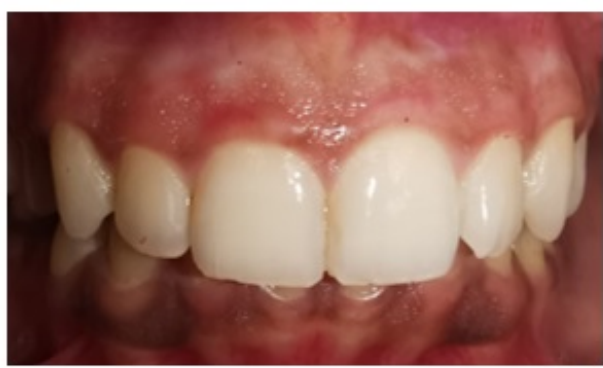

\section{Results:}

A total of fifteen patients (4 males and 11 females) diagnosed clinically with diffuse clinical gingival pigmentation ranging from moderate to heavy pigmentation (DOP score 2-3) involving the facial aspect of the maxillary right to left premolar area, were enrolled in the study. Their ages ranged from 18 to 35 with mean age of 25.53 years ( $+/-4.12)$. No patients dropped out.

Eight patients had the right maxillary quadrant allocated as "study site" and the left as "control site". The other seven patients had the left maxillary quadrant allocated as "study site" and the right as "control site". 
All patients were followed up for one year and the results were registered as: clinical variables.

\section{Clinical Results:}

During the twelve months of postoperative follow up, all patients from the selected sample showed no postoperative inconveniences.

Wilcoxon Signed Ranks Test is a non-parametric statistical hypothesis test. It is used to compare the repeated measurements on a single sample. It is a nonparametric test that can be used to determine whether two dependent samples were selected from populations having the same distribution. The test was used because data are paired and come from the same population, each pair is chosen randomly and independently, and the data are measured on an interval scale.

Pain was measured during surgery and after the third and seventh days. Variations in pain were compared between those on the study site (diode laser) and control site (scalpel) (figures 13, 14a, and 14b). A Wilcoxon signed-rank test was conducted. There were significant differences between scalpel and laser during surgery $(\mathrm{Z}=-2.858, \mathrm{p}=0.004)$, and during the first three days $(\mathrm{Z}=$ -2.121, $p=0.034)$. However, there was no significant difference between scalpel and laser on day seven $(Z=0.000, p=1)$ (table 2$)$.

Table 2: Test Statistics of Pain.

\begin{tabular}{|c|c|c|c|}
\hline \multicolumn{4}{|c|}{ Test Statistics ${ }^{\mathrm{a}}$} \\
\hline & $\begin{array}{c}\text { Scalpel day } 0 \text { - } \\
\text { Laser day } 0\end{array}$ & $\begin{array}{c}\text { Scalpel day } 3 \text { - } \\
\text { Laser day } 3\end{array}$ & $\begin{array}{c}\text { Scalpel day } 7 \text { - } \\
\text { Laser day } 7\end{array}$ \\
\hline $\mathbf{Z}$ & $-2.858^{\mathrm{b}}$ & $-2.121^{c}$ & $.000^{\mathrm{d}}$ \\
\hline $\begin{array}{l}\text { Asymp. Sig. } \\
\text { (2-tailed) }\end{array}$ & 0.004 & 0.034 & 1.000 \\
\hline \multicolumn{4}{|c|}{ a. Wilcoxon Signed Ranks Test } \\
\hline \multicolumn{4}{|c|}{ b. Based on positive ranks. } \\
\hline \multicolumn{4}{|c|}{ c. Based on negative ranks. } \\
\hline \multicolumn{4}{|c|}{ d. The sum of negative ranks equals the sum of positive ranks. } \\
\hline
\end{tabular}


Figure 13: Box plot graph showing variations in the median of the degree of pain between laser and scalpel during surgery, three days and seven days after surgery.

$$
\text { Pain }
$$

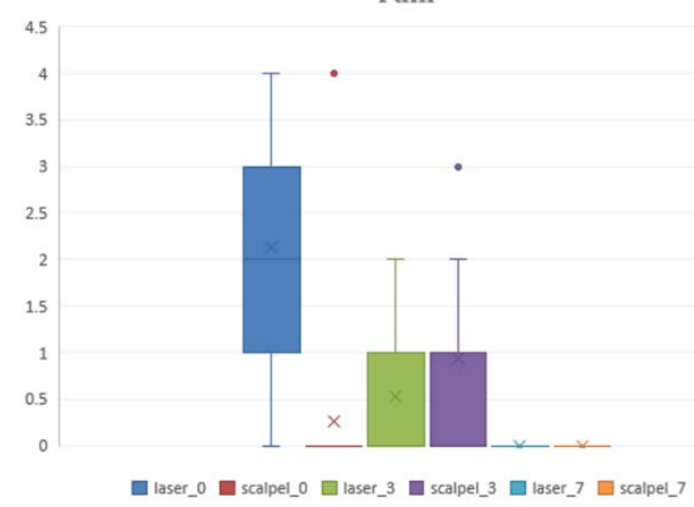

Figure 14a: Line graph showing variations in pain upon scalpel during surgery, three and seven days after.

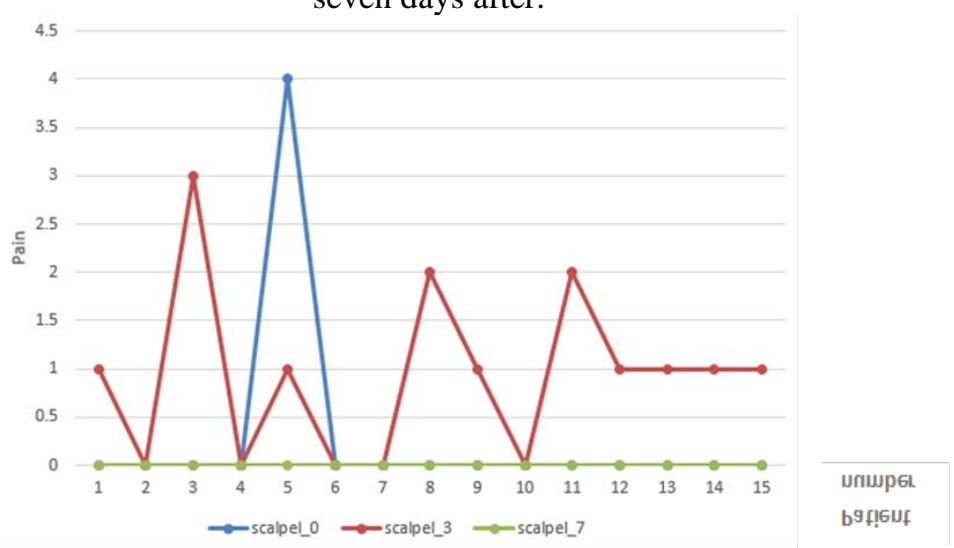

Figure 14b: Line graph showing variations in pain upon laser during surgery, three and seven days after.

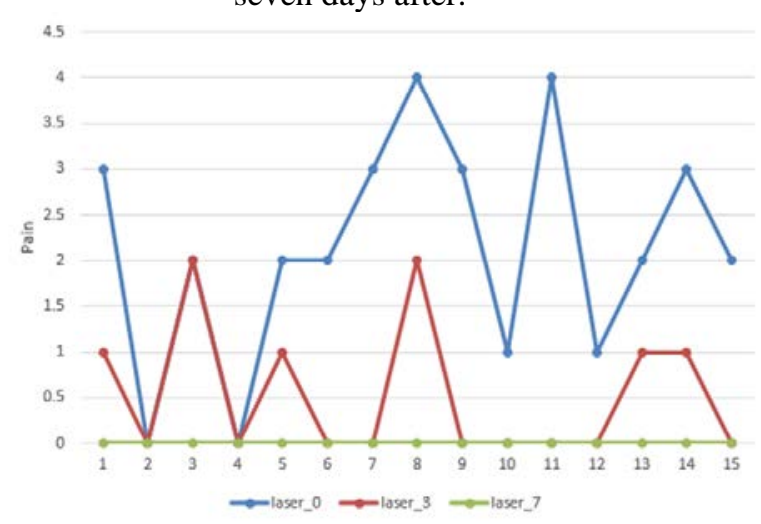


Bleeding was assessed and recorded directly after both procedures (figure 15). A Wilcoxon Signed Ranks Test was conducted. There was significant difference between scalpel and laser $(Z=-3.626, p=0.000)$, where the record was zero (no bleeding) with laser with all patients, where as it varied between 1 (oozing) and 2 (active bleeding) with scalpel (table 3).

Table 3: Test statistics of bleeding.

\begin{tabular}{|c|c|}
\hline & Test Statistics $^{\text {a }}$ \\
\hline S & Scalpel - Laser $^{\mid}$ \\
\hline $\begin{array}{c}\text { Asymp. Sig. (2- } \\
\text { tailed) }\end{array}$ & $-3.626^{\mathrm{b}}$ \\
\hline a. Wilcoxon Signed Ranks Test \\
\hline \multicolumn{2}{|c|}{ b. Based on negative ranks. } \\
\hline
\end{tabular}

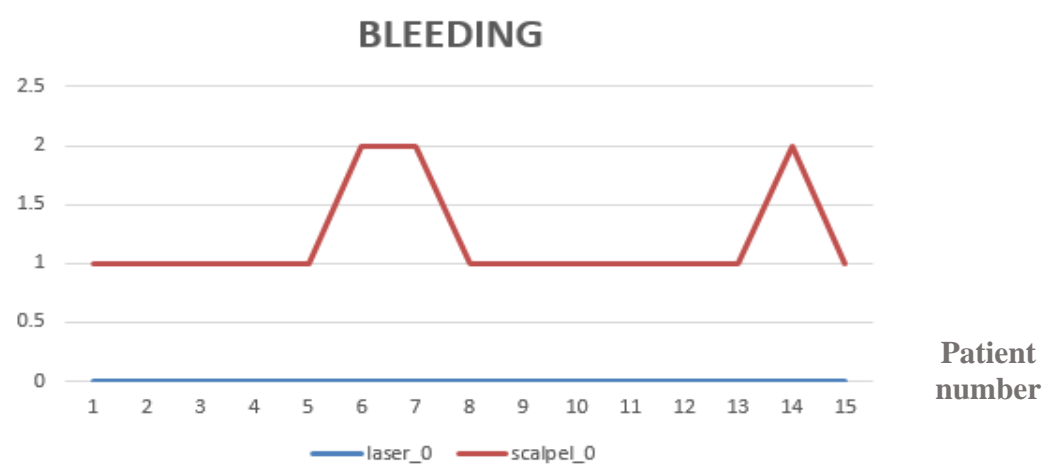

Figure 15: Line graph showing variations in bleeding between laser and scalpel surgeries.

Duration of the procedure was measured in minutes (figure 16). A Wilcoxon Signed Ranks Test was conducted. There was significant difference between scalpel and laser $(Z=-2.675, p=0.007)$. It was evident that scalpel procedure took more time in most cases than the laser procedure (table 4).

Table 4: Test statistics of duration of procedure.

\begin{tabular}{|c|c|}
\hline \multicolumn{2}{|c|}{ Test Statistics ${ }^{\mathbf{a}}$} \\
\hline & Scalpel 0 - Laser 0 \\
\hline $\mathbf{Z}$ & $-2.675^{b}$ \\
\hline $\begin{array}{l}\text { Asymp. } \\
\text { Sig. (2- } \\
\text { tailed) }\end{array}$ & .007 \\
\hline & igned Ranks Test \\
\hline
\end{tabular}




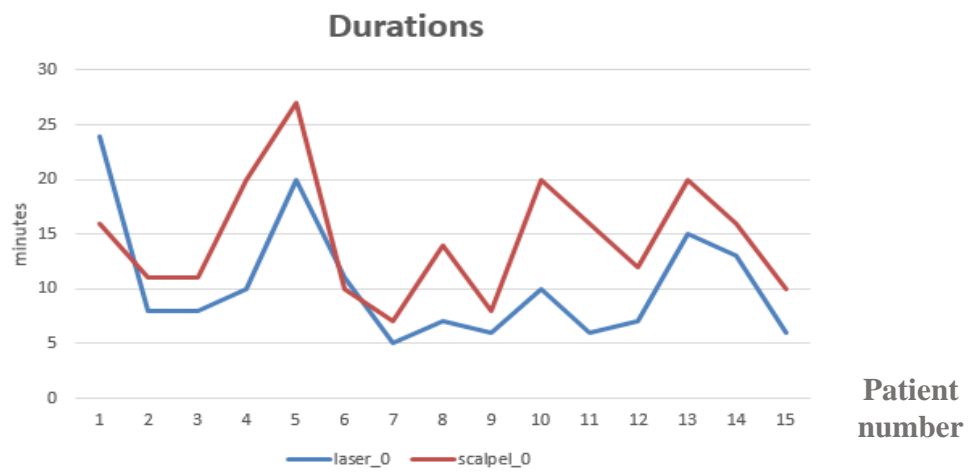

Figure 16: Line graph showing variations in duration of procedure between laser and scalpel surgeries.

Wound healing on both sites was assessed and compared on the third and seventh days post-operative (figure 17). A Wilcoxon Signed Ranks Test was conducted. There was no significant difference between scalpel and laser on the third day $(\mathrm{Z}=-1.890, \mathrm{p}=0.059)$ nor on the seventh day $(\mathrm{Z}=0.000, \mathrm{p}=$ 1.000) (table 5).

Table 5: Test statistics of wound healing.

\begin{tabular}{|c|c|c|}
\hline \multicolumn{2}{|c|}{ Test Statistics $^{\mathrm{a}}$} \\
\hline Scalpel 3 - laser_3 & $\begin{array}{c}\text { Scalpel 7 - } \\
\text { laser_7 }\end{array}$ \\
\hline Z & $-1.890^{\mathrm{b}}$ & $.000^{\mathrm{c}}$ \\
\hline $\begin{array}{c}\text { Asymp. Sig. (2- } \\
\text { tailed) }\end{array}$ & .059 & 1.000 \\
\hline \multicolumn{2}{|c|}{ a. Wilcoxon Signed Ranks Test } \\
\hline \multicolumn{2}{|c|}{ b. Based on negative ranks. } \\
\hline c. The sum of negative ranks equals the sum of positive ranks.
\end{tabular}

Figure 17: Compound bar graph showing variations in wound healing between laser and scalpel surgeries on third and seventh days.

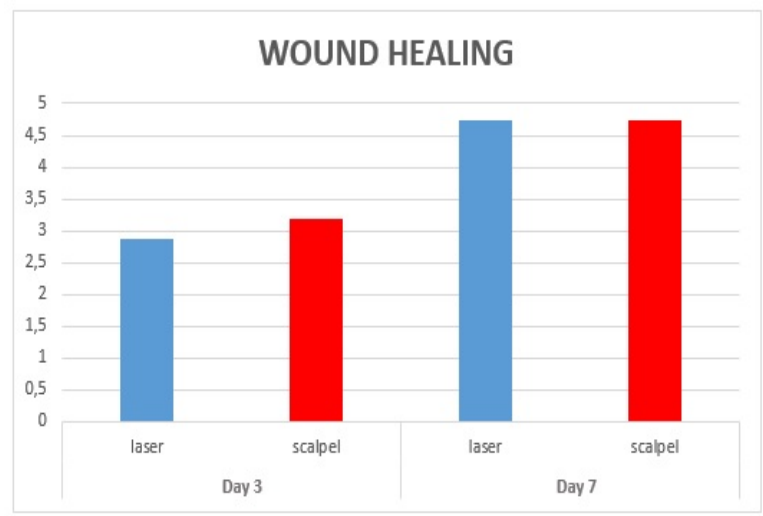


Gingival pigmentation was assessed according to DOP index at baseline, three, six, and twelve months for appearance of repigmentation (figure 18). A Wilcoxon Signed Ranks Tests were conducted. There was no significant difference between scalpel and laser on the third month $(Z=-1.414, p=0.157)$, yet there were significant differences on the sixth month $(Z=-2.000, p=0.046)$ and the twelfth month $(\mathrm{Z}=-2.121, \mathrm{p}=0.034)$ for the benefit of laser (table 6).

Table 6: Test statistics of DOP score.

\begin{tabular}{|c|c|c|c|c|}
\hline \multicolumn{5}{|c|}{ Test Statistics ${ }^{\mathrm{a}}$} \\
\hline & $\begin{array}{l}\text { Scalpel } 0 \text { - } \\
\text { Laser } 0\end{array}$ & $\begin{array}{c}\text { Scalpel } 3 \text { - } \\
\text { Laser } 3\end{array}$ & $\begin{array}{l}\text { Scalpel } 6 \text { - } \\
\text { Laser } 6\end{array}$ & $\begin{array}{l}\text { Scalpel } 12 \\
\text { - Laser } 12\end{array}$ \\
\hline $\mathbf{Z}$ & $.000^{\mathrm{b}}$ & $-1.414^{\mathrm{c}}$ & $-2.000^{c}$ & $-2.121^{\mathrm{c}}$ \\
\hline $\begin{array}{c}\text { Asymp. Sig. } \\
\text { (2-tailed) }\end{array}$ & 1.000 & .157 & .046 & .034 \\
\hline \multicolumn{5}{|c|}{ a. Wilcoxon Signed Ranks Test } \\
\hline \multicolumn{5}{|c|}{ c. Based on negative ranks. } \\
\hline
\end{tabular}

Figure 18: Compound bar graph showing variations in DOP score between laser and scalpel from baseline (zero) to twelve months.

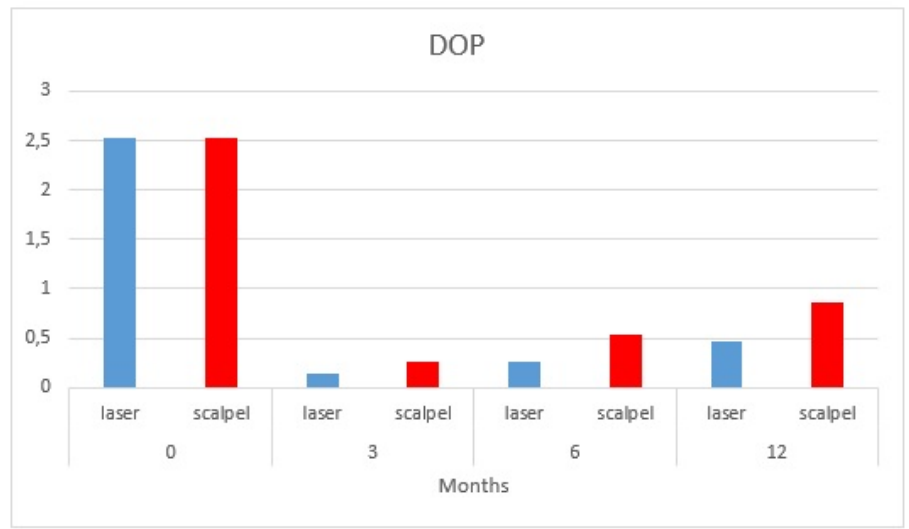

\section{Discussion:}

Various methods have been used for depigmentation, each with its own merits and limitations. Gingival depigmentation performed in this study with a blade (scalpel technique) was precise, definite and under control. With this technique, it was possible to appreciate the depigmented areas immediately and did not leave room for any residual pigments. However, this technique required the use of local anesthesia, resulted in hemorrhage and required immense care while excising the epithelium in order not to expose the bone or create gingival recession. Comparatively, the use of the scalpel technique for depigmentation is the most economical as compared with other techniques that require more advanced armamentarium (Bhusari and Kasat, 2011). 
Laser light at $800-900 \mathrm{~nm}$ is poorly absorbed in water but highly absorbed in hemoglobin and other pigments (Cobb 2006). Since the diode laser does not interact with dental hard tissues, the diode laser is an excellent soft tissue surgical laser, indicated for cutting and coagulating gingival and oral mucosa. The diode laser exhibits "hot-tip" effect caused by heat accumulation at the end of the fiber, and produces a relatively thick coagulation layer on the treated surface.

The visual analog scale was used to assess the pain perception during and after the treatment. Laser depigmentation procedure as compared to scalpel procedure had higher pain scores during the procedure, and that is due to the difference in anesthesia application. During the following three days, postoperative pain on laser sites was significantly less than on scalpel sites ( $\mathrm{p}=$ 0.034). The increased pain perception associated with the scalpel might be attributed to the fact that it is a more intrusive surgical procedure involving blood loss and a wide open surgical wound. On day seven, there was no statistical significant difference between both groups in terms of pain perception $(p=1>0.05)$. The findings of the present study run parallel to the study conducted by Suragimah et al. (2016), who concluded that postoperative pain experienced by the patients with laser treatment was less compared to scalpel technique during the first days only, but on the seventh day, there is no difference between the two techniques.

In this study, bleeding during surgery was assessed between both techniques. Laser treated sites showed no bleeding unlike the scalpel treated sites. The findings of the present study are consistent with the studies conducted by Lagdive et al. (2009) and Lee et al. (2011). This may be because laser has the ability to cut and coagulate tissues. The protein coagulum formed on the wound surface acts as a biological dressing and seals the ends of the capillaries and venules, reducing the bleeding during laser surgery.

Comparison of the duration taken by each procedure by the operator showed that laser technique took less time. Laser technique was easy to perform due to absence of bleeding during the operative surgery and was less technique-sensitive compared to scalpel technique. The difference was statistically significant $(\mathrm{p}=0.007)$. The result of the current study is comparable to the study conducted by Simsek Kaya et al. (2012).

Wound healing was assessed on day three and day seven. On day three, scalpel treated sites showed faster healing compared to laser treated sites, but this did not reach a statistically significant level $(\mathrm{p}=0.059)$. The findings of the present study are consistent with the study conducted by Kasagani et al. (2012). In both techniques, evaluation on day seven revealed restoration of normal features of the gingiva without any scar formation. Thus the healing of depigmented gingiva was uneventful irrespective to the techniques used. 
Melanin pigmentation score was evaluated by DOP index preoperatively, three months, six months, and twelve months postoperatively. The results of evaluation of repigmentation after three months did not show statistically significant difference between both sites $(\mathrm{p}=0.157)$. At six and twelve months, repigmentation at laser sites was significantly less than that occurred on scalpel sites $(\mathrm{p}=0.046$ and $\mathrm{p}=0.034)$. The decreased intensity of pigmentation may be due to the lesser production of pigments. The intensity may increase with time and may reach to pre-treatment level as it depends on the racial background of the patient. The results are consistent with the finding of Bergamaschi et al. (1993), who demonstrated that permanent results cannot be offered when gingival depigmentation procedures are performed for cosmetic reasons.

The mechanism of repigmentation is still not understood, but according to the migration theory, active melanocytes from the adjacent pigmented tissues migrate to the treated areas, causing failure. Reports of repigmentation are quite limited and varied.

Several limitations were faced during the conduction of this study, among which is collecting patients with hyper-pigmented gingiva in the Middle Eastern sector. Moreover, meeting the non-smokers exclusion criteria was challenging since a significant portion of the Lebanese population are heavy smokers (either cigarettes or hookah). In addition to that, it can be harder to convince patients to go through an esthetic procedure than convincing them with a treatment of a disease procedure. Last but not least, scheduling a followup appointments was tough, numerous phone calls were required because the patients came from different regions of the country.

\section{Conclusion:}

As per this study, gingival pigmentation is effective with both scalpel and laser techniques. Laser treated sites showed reduced pain experienced by patient during the first three days only. As for the operator comfort, it was better in case of laser technique compared to scalpel technique, due to absence of bleeding and ease of use. Both techniques did not result in any postoperative complication and the gingiva healed uneventfully. Recurrence rate of gingival repigmentation was faster in scalpel technique as compared to laser technique.

\section{References:}

1. Bansal, M., Kumar, A., Puri, K., Khatri, M., Gupta, G., \& Vij, H. (2016). Clinical and histologic evaluation of platelet-rich fibrin accelerated epithelization of gingival wound. Journal of Cutaneous and Aesthetic Surgery, 9(3):196-200 
2. Bergamaschi, O., Kon, S., Doine, AI., \& Ruben, MP. (1993). Melanin repigmentation after gingivectomy: A 5-year clinical and transmission electron microscopic study in humans. Int J Periodontics Restorative Dent, 13(1):85-92

3. Bhusari, BM., \& Kasat, S. (2011). Comparison between scalpel technique and electrosurgery for depigmentation: A case series. J Indian Soc Periodontol, 15(4): 402-5

4. Bortuluzzi, EA., Araujo, GS., Guerreiro Tanomaru, JM., \& TanomaruFilho, M. (2007). Marginal gingival gingival discoloration by gray MTA: A case report. J Endod, 33:325-7

5. Carlos-Bregni, R., Contreras, E., Netto, AC., Mosueda-Taylor, A., \& Vargas, PA. (2007). Oral melanoacanthoma and oral melanotic macule: A report of 8 cases, review of literature, and immunohistochemical analysis. Med Oral Patol Oral Cir Bucal, 12:E374-9

6. Chawla, K., Lamba, KL., Tandon, S., Faraz, F., \& Gaba, V. (2016). Effect of low-level laser therapy on wound healing after depigmentation procedure: A clinical study. J Indian Soc. Periodontol., 20(2):184-8

7. Cobb, CM. (2006). Lasers in periodontics: A review of the literature. J Periodontol, 77:545-64

8. Dummett, CO., \& Gupta, OP. (1964). Estimating the epidemiology of gingival pigmentation. J Natl Med Assoc, v.56 (5): 419-20

9. Fiorelline, JP., Kim, DM., \& Uzel, NG. (2011). Anatomy of the periodontium: newmann, takei, Klokkevoid, Carranza. In: Carranza's clinical periodontology, eleventh ed. Elsevier, pp. 12-27

10. Harpreet, SG., Dadlani, H., Bhardwaj, A., Yadav, Anil., \& Lal, Sanjay. (2014). Evaluation of patient response and recurrence of pigmentation using laser and scalpel technique: A clinical study. Journal of Indian Society of Periodontology, 18(5):586-92

11. Hedin, CA., \& Larsson, A. (1987). Large melanosome complexes in the human gingival epithelium. J Periodontal Res, 22:10813-21

12. Javali, MA., Tapashetti, R., \& Deshmukh, J. (2011). Esthetic management of gingival hyperpigmentation: Report of two cases. Int J Dent Clin, 3(2):115-6

13. Kasagani, SK., Nutalapti, R., \& Mutthineni, RB. (2012). Esthetic depigmentation of anterior gingiva - A case series. N Y State Dent J, 78:26-31.

14. Kauzman, A., Pavone, M., Blanas, N., \& Bradley, G. (2004). Pigmented lesions of the oral cavity: review, differential diagnosis of case presentation. J Can Dent Assoc, 70(10):682-3 
15. Kumar, S., Bhat, S., \& Bhat M (2013). Comparative evaluation of gingival depigmentation using tetrafluoroehtane cryosurgery and gingival abrasion technique: Two years follow up. J Clin Diagnostic Res, 7:389-94

16. Lagdive, S., Doshi, Y., \& Marawar, PP. (2009). Management of gingival hyperpigmentation using surgical blade and diode laser therapy: A comparative Study. J Oral Laser Appl, 9:41-47

17. Lee, KM., Lee, DY., Shin SI., Kwon, YH., Chung, JH., \& Herr ,Y. (2011). A comparison of different gingival depigmentation techniques: Ablation by erbium: yttrium-aluminum-garnet laser and abrasion by rotary instruments. J Periodont Implant Sci, 41(4):201-7

18. Malhotra, S., Sharma, N., \& Basavaraj, P. (2014). Gingival esthetics by depigmentation. J Periodontal Med Clin Pract, 1:79-84

19. Meleti, M., Vescovi, P., Moori, WJ., \& Van Der Waal, I. (2008). Pigmented tissues of the oral mucosa and perioral tissues: A flow chart for diagnosis and some recommendations for the management. Oral Surg Oral Med Oral Pathol Oral Radiol Endod, 105:606-16

20. Pippi, R. (2017). Post-surgical clinical monitoring of soft tissue wound healing in periodontal and implant surgery. Int J Med Sci, 14(8):721-8

21. Prabhuji, M., Madhupreetha, S., \& Archana, V. (2011). Treatment of gingival hyperpigmentation for aesthetic purposes using the diode laser. Laser, 2:18-9

22. Simsek Kaya, G., Yapici Yavuz, G., Sümbüllü, MA., \& Dayi, E. (2012). A comparison of diode laser and Er:YAG lasers in the treatment of gingival melanin pigmentation. Oral Surg Oral Med Oral Pathol Oral Radiol, 113:293-9

23. Suragimah, G., Lohana, MH., \& Varrna, S. (2016). A split mouth randomized clinical comparative study to evaluate the efficacy of gingival depigmentation procedure using conventional scalpel technique or diode laser. Journal of Lasers in Medical Sciences, 7(4)

24. Varghese, KG., Manoharan, S., \& Sadhanandan, M. (2015). Evaluation of bleeding following dental extraction in patients on longterm antiplatelet therapy: A clinical trial. Indian J Dent Res, 26(3):252- 